\title{
Are National Health Services Systems Converging? Predictions for the United States
}

\author{
By OdIN W. ANDERSON
}

\begin{abstract}
A review of the emerging literature on crossnational health services systems and first hand studies by the author reveals that health services systems in many countries are converging in their egalitarian objectives, organizational forms, methods of paying providers, scope of services, and costs controls. Cross-nationally facilities and personnel are quite similar, indicating the importance of medical technology as a shaping force. Organizational forms, methods of payment, and sources of funding differ widely because these are mainly social and political expressions, but these too, are converging. Countries will continue to exhibit differences in structuring inherent in their economic and political styles, from the United States to the U.S.S.R. It is proposed that the range of difference will narrow, but not converge. Several issues are examined cross-nationally: equity, scope of services, financing and cost controls, organizational structure, and planning. Finally, predictions of developments in the United States are made from experiences in other countries, and from the social, economic, and political style of the United States.
\end{abstract}

Odin W. Anderson is a sociologist engaged in research and teaching in the organization and financing of health services. He received his Ph.D. at the University of Michigan in 1948. He has been on the faculties of a school of public health, (Michigan) and a medical school, (University of Western Ontario). He is presently Professor of Sociology in the Graduate School of Business and the Department of Sociology, as well as Director of the Center for Health Administration Studies at the University of Chicago. His current major interest is comparative health systems is explored in Health Care: Can There Be Equity? The United States, Sweden, and England.

This paper was produced with the support of the Programmatic Grant HS 000880-11 National Center for Health Services Research. 
$I^{T}$ T IS frequently remarked that the United States is the only industrialized country in the world that has not enacted universal health insurance and does not have a national health policy. It is supposed to follow, then, that countries that do have universal health insurance also have a national health policy and are coping more adequately than the United States with the issues of equal access, adequate funding, adequate controls on quantity and quality of services. These assumptions are, at best, only partly true. What other countries have accomplished is to eliminate the fear of high cost episodes to families which would endanger their financial solvency, and to a higher degree, but far from equitably, spread the cost over income groups so that the better-off are likely to contribute more than the worse-off. These are, of course, basic accomplishments, but, currently, other countries are almost forgetting them in their concern with health service expenditures encroaching unduly on other internal problems facing the nations. This country is encountering all current health problems simultaneously-rising costs, increased use, equal access, equal distribution, and proliferating technology, while it is contemplating some form of universal health insurance. Other countries enacted universal health insurance when the cost trends were rising slowly and egalitarian issues were not being pressed as ardently as now. The basic objective was to finance as demanded, and when that proved too costly, later, as needed, and now, as can be afforded, the latter basically a political decision. As for a national health policy, other industrialized countries do not have one either in any specific sense of goals and methods to achieve them with what resources, by what standards of achievement, and at what cost. Perhaps the USSR comes as close to an explicit national health policy as any industrialized country with methods and goals spelled out in five year plans. ${ }^{1}$

The universal objective everywhere is to equalize access to services and to take the burden of costly episodes off families. These measurable, essentially social and political, objectives are obscured and obfuscated by the utopian objectives of raising health levels when their indicators are so crude they show little, if any, measurable effect in industrialized countries since their conquest of infectious and communicable diseases has turned the leading causes of death upside down since the turn of the century.

\section{INTRODUCTION}

I intend by this introduction to approach universal health insurance in an international context, issue by issue, historically and currently, and, in both, cross-nationally. I will draw on various disciplines: history, economics, political science, sociology, and even ethics, without referring to them as suchthe privilege of the synthesist.

Each discipline, except possibly history, is too specialized; it deals with too few variables (only the measurable kind) for an overview of human behavior in relation to a particular human enterprise, from healing to war. The synthesist thus needs

1. Odin W. Anderson, "Health Services in the USSR," Selected Papers, no. 42 (Graduate School of Business, University of Chicago, 1973) and Igor V. Pustovoy, "Health Care Planning in the USSR: Its Role in Improving Medical and Preventive Services (Michael M. Davis Lecture, Center for Health Administration Studies, Graduate School of Business, University of Chicago, 1975). 
to be arrogant, because this source material does not come in neatly documented packages, and he necessarily formulates his conceptual framework on a high level of abstraction.

In recent years there has been a burgeoning interest in health service systems in various countries. The studies on them have been usually case reports of single countries, but the emerging approach is comparative. Also, the studies are largely descriptive, setting forth the current organizational structure and expenditure sources with little attempt at developmental histories or analysis of the effect of particular social, economic, and political conditions. ${ }^{2}$ Still, the trend is toward increased interest and sophistication in both case studies and comparative research. ${ }^{3}$ In addition, there are

2. See, for example, John Fry, Medicine in Three Societies: A Comparison of Medical Care in the USSR, USA, and UK (New York: Elsevier, 1970); Alan Maynard, Health Care in the European Community (London: Croom Helm, 1975); M. Kaser, Health Care in the Soviet Union and Eastern Europe (London: Croom Helm, 1976); Karl Evang, David S. Murray, and Walter J. Lear, Medical Care and Family Security: Norway, England, and the U.S.A. New York: Prentice-Hall, 1963). See also "Health: A Major Issue," Scandinavian Review (1975). Selected experiences from Scandinavian countries may be found in this article.

3. Perhaps a starter was Henry E. Sigerist, Socialized Medicine in the Soviet Union (New York: Norton, 1937), retrospectively, a rather romanticized version, but followed later by Mark G. Field, Doctor and $\mathrm{Pa}$ tient in Soviet Russia (Cambridge, Mass.: Harvard University Press, 1957); Gordon Forsyth, Doctors and State Medicine; A Study of the British Health Services (Philadelphia: Lippincott, 1966); Odin W. Anderson, Health Care: Can There Be Equity? The United States, Sweden, and England (New York: Wiley, 1972); Spyros Andreopoulos, ed., National Health Insurance: Can We Learn From Canada? (New York: Wiley, 1975); Romuald K. Schicke, “Die Stellung des Arzte in Systems der Gesell- comparative studies of patterns of use of services which are useful for systems operation comparisons. ${ }^{4}$ All these studies are drawn on directly or indirectly in the course of this paper, as is the historical literature on social, economic, and political history in Europe and North America. Hence, I will not document this aspect, but simply suggest that obviously my conceptual framework is primarily tuned to liberaldemocratic and social-democratic societies where the industrial revolution resulted in the destruction of the mercantile state, and the emergence of pluralistic interest group power centers and mixed private and

schaflichen Sicherung in der Bundesrepublic Deutschland, in England und in den USA und ihre Bedeutung fur dre Versorgung mit Gesundheitsgutern," (Diss., University of Hamburg, 1969); Christa Altenstetter, "Planning for Health Facilities in the U.S. and in West Germany," Milbank Memorial Fund Quarterly: Health and Society, 51 (Winter 1973), pp. 41-71. Ray H. Elling, "Health Planning in International Perspective," Medical Care, 9 (May-June, 1971) pp. 214-34; John H. Babson, Health Care Delivery Systems: A Multinational Survey (Bath, England: Pitman Medical, 1972); Theodore J. Litman and Leonard L. Robins, "A Comparative Analysis of Health Care Systems: A Socio-Political Approach," Social Science and Medicine, 5 (December 1971), pp. 573-81; William A. Glaser, Social Settings and Medical Organization: A Cross-National Study of the Hospital (New York: Atherton Press, 1970).

4. See, Robert Kohn and Kerr White, eds., Health Care: An International Survey (London: Oxford University Press, 1976); Ronald Andersen, Bjorn Smedby, and Odin W. Anderson, "Medical Care Use in Sweden and the United States," Research Series, no. 26 (Center for Health Administration Studies, University of Chicago, 1969); A Mizrahi and A. Mizrahi, L'enquete de 1970 sur les Consommations Medicales (Paris: Centre de Recherches et de Documentation sur la Consommation, 1976); Tapani Purola, Esko Kalimo, and Kauko Nyman, Health Services Use and Health Status under National Sickness Insurance (Helsinki: Research Institute for Social Security, 1974). 
public sectors. These economic and political changes shaped the health services in western countries; other traditions have shaped the systems in countries in the orbit of the USSR sphere of influence.

This paper will be then in large part conceptual, but still I hope it will have sufficient grounding in actual historical developments so that further research will fill out this framework without modifying it in substance. Further, there are now probably a sufficient number of detailed descriptions of national systems and litanies of woe that inferences can be made as to what is in store for the United States. Finally, I will try to show that regardless of the economic and political context, there is a strain toward similar concepts of organizing, funding, and controlling personal health services systems.

I will review a series of issues which appear to be generic in all health services systems. They are: (1) equity; (2) scope of services; (3) organizational structure and finance; (4) cost and quality controls, and (5) planning. The management of these issues in other countries which are chronologically ahead of the United States may reveal what the United States will experience as this country moves into some form of universal health insurance.

Before embarking on these issues, it is useful to note that in general the various service components comprising a modern personal health services system are quite similar across industrialized countries, certainly similar enough for the purpose of this paper. Hospitals, physicians and specialties within them, nurses and pharmacists are easily recognizable cross-nationally; and in substance they perform more or less the same tasks. It can be rea- sonably assumed that these types of facilities and personnel have been shaped by medical science and technology into some division of medical-scientific labor congruent with this knowledge and technology. Very wide variations emerge in how these facilities and personnel are related to each other in organizational structures, how they are paid, what autonomy they enjoy, how the entire system is financed from what sources in what proportions and what rights and method of access are given the general public. These considerations emerge largely out of the economic and political traditions regarding property rights, private market versus political bargaining, and the role of the government. Personal health services have never been purely a private profit marketplace enterprise in any country. Even where hospitals are privately owned, and physicians are autonomous contractors for their services, society has expected them to provide care to all seekers regardless of means. Undoubtedly, this expectation frequently has not been fulfilled, but the basic value persists. Eventually, the concept of equality of access found expression through governmentally sponsored health insurance, the presumed ultimate custodian of the public's welfare.

\section{THE Issue OF EquITY}

Equity has been the underlying value for the development of the welfare state after the inequities of the industrial revolution became political issues; i.e., loss of income because of unemployment, disability and old age. Later, health services became unpredictable and costly for the household, and were therefore merged with the income transfer concept of the welfare state. Simple income transfer is not the 
only issue in the provision of health services. A complex service by high status professionals is also involved. The welfare state measures taken by industrial societies cut across ideology from liberal-democratic to communistic. ${ }^{5}$ The problems are inherent in industrialism; ideological differences appear in the means and rights accorded the public. Health services appear to have aroused more ideological controversy than simple income transfer because of basic values of professional autonomy and range of choice by the public, as well as others.

Equity eventually became defined as equality. In Great Britain, for example, it was thought equitable in 1911 to introduce for workers under certain incomes a general practice plan excluding their dependents. It was reasoned that workers should be kept healthy so that they could be more productive for both society and their dependents. If hospital care were needed, all could receive it at the voluntary hospitals which were subsidized by the rich for the working class. Publicly supported hospitals were built for the paupers, by definition, the unworthy poor as contrasted with working and, therefore worthy, poor. Private hospitals and private beds in the voluntary hospitals served the small upper class. This system was politically endured until the 1940s, as the concept of equality began to find political expression in universality and the National Health Service.

In the United States, an emergency charity health services for

5. See, Harold L. Wilensky, The Welfare State and Equality; Structural and Ideological Roots of Public Expenditures (Berkeley: University of California Press, 1975) and Morris Janowitz, Social Control of the Welfare State (New York: Elsevier, 1976). the poor and a private system for the mass of the public were regarded as equitable until the drive for some sort of universal and national health insurance surfaced. Again, the concept of equity changes to equality. Similar developments with differences only in degree took place on the continent. In the Scandinavian countries, on the other hand, health services, particularly hospital care (including physicians' services in the hospital), were regarded as a total community service by at least the turn of the nineteenth century. The hospitals were, and are, owned by the local county governments. Reasons for the different concepts of equity in time and place are not easy to elucidate. They flow out of the class system, of the political views and time, and appear to change as suffrage is expanded to all adults.

When universal health insurance systems were established, the underlying rationale was that of protecting the household from costly and unpredictable medical care episodes, equity through sharing risks. Universality was, therefore, taken for granted. This principle was easy to accept, but other equity issues came to the fore, such as how to share the cost from general revenue and/or employee-employer payroll deductions, making health services a part of the cost of production. The more egalitarian proponents strove for a progressive income tax, the more pragmatic for payroll and sales taxes, which are by their nature regressive. The USSR simply applied part of the surplus income from her state enterprises because she owns all the means of production and distribution. As can be imagined, in the western democracies there is a mixture of sources of funding, with a standoff, by and large, between per- 
sonal and progressive income tax, payroll taxes and sales taxes. The United States and Great Britain are the extremes among western countries with the United States relying largely on payroll taxes and Great Britain on the progressive income tax. The mixture of funding sources is likely to continue.

Another issue that has emerged quite recently in universal health insurance is that of equal distribution of services geographically as well as equal access, by the elimination of cost, to the household at time of service. Universal health insurance or service was inaugurated at a time (except for the USSR) when the health services infrastructure was already in essence established. Naturally, there were more hospitals and physicians in Paris, London, Stockholm, Berlin, Chicago, New York, Philadelphia and Toronto than in the hinterlands. Further, there were differences even within cities. These disparities in distribution have been improved, only in part, since the inception of universal health insurance. Equal distribution is now a political issue and has recently been expressed through great interest in planning. If the method is only to increase services in underserviced areas to bring them up to the level of well-serviced areas, such areas would not complain except perhaps about the higher taxes that would be required. If the method is to reduce services in wellserviced areas and increase them in underserviced areas, a political issue of the first magnitude arises between sectional interests. The latter method is now in effect in Great Britain through the central budgeting process, and it is so incremental (a few percentage points more or less over a twenty-five year period) that it will take a whole generation to notice, by which time everyone will be accustomed to relatively equal distribution.

\section{The Issue of Scope of Services}

Universality is now taken for granted in all countries, but the scope of services is still debated. All countries except Great Britain in 1946 and the USSR, since its first five-year plan beginning in the thirties, have been selective in their scope of services paid for or provided through the universal health insurance system. Health services, by definition, included all professionally recognized services: hospital, physician, nursing, dentistry, and drugs and medicines. Great Britain included everything as part of the euphoria of World War II togetherness and the continuing tradition of noblesse oblige. The USSR introduced universal coverage for ideological reasons inherent in communist philosophy. The United States started with universality for an age group, those sixty-five years and over, and hospital and physicians' services, with relatively high deductibles. Canada started with a service component, hospital services, excluding physicians' services in hospitals, for all citizens. Scandinavia started with hospital care for all citizens including inhospital physicians' services. Australia started with prescription drugs. In general, it can be said that industrialized countries have, by and large, started universal health insurance with hospital and physician services, later trying to add drugs and medicine, dental care, home care, and long-term care. There has been and continues to be an understandable fear by government to overcommit its taxing power and available resources. 
The strain is toward comprehensiveness so that in time all recognized professional health services will likely be covered in some form. It appears that people everywhere are loathe to pay for any services directly, even though they may be relatively small charges over a period, such as deductibles and coinsurance, with the insurance system paying for higher magnitude costs. People do not equate costs of health services with life and casualty, or automobile insurance. So far, the United States appears to be the most insurance, rather than service, conscious nation, but the trend toward comprehensiveness persists in this country as well.

\section{The Issue of Financing AND Cost ConTrols}

The problem of financing and cost controls are discussed separately from organizational structure, because they were grafted on to the existing health service delivery structure in all countries as some form of universal health insurance was established, particularly on the continent and among the commonwealth countries. The existing delivery structure was taken as a given; the primary problem was regarded as financing. Great Britain is a partial anomaly in that she regionalized her hospitals and established salaried specialists in the hospitals in 1948, a new departure, but even so, one gets the impression that the basic structure remained, although the ownership shifts exclusively to the central government. The tripartite organizational and budgeting structures of general practice, hospitals and their salaried specialists, and the local public health services reflect historical interests and patterns which are embodied in the
National Health Service. It is only recently that Great Britain has abolished the tri-partite structure in order to facilitate utilization of all services within single regions. Even so, general practitioners still have a separate budget in the national system.

Funding sources in the western industrialized countries remain diverse because parliamentary governments must pay due regard to the sensitivity of the body politic to taxing methods, who is to be taxed, and how much. All systems generally started with payroll deduction as an easy source of income, thereby keeping it separate from general revenue usually based on personal and progressive income tax. In the early days, the personal income tax did not even exist. Further, taxation at the employer-employee level was regarded as a cost of production. In economies like that of the USSR, of course, health services are financed from the profits of state enterprises. It is not reflected in the employees' incomes, but simply regarded as a service naturally financed through public funds from state surpluses. In other countries, the continuing private-public sector economies, although increasingly blurred, are then naturally reflected in the politics of financing health services, as well as other transfer types of payments. As long as there is private ownership of the means production and distribution, there will likely be a plurality of funding sources: employer-employee, general revenue, sales taxes, and possibly some direct payment at time of service. General revenue will probably continue to split between progressive personal income tax and various forms of sales taxes. It seems reasonable to predict that the progressive income tax as a source 
of revenue will encounter increasing political hostility at the polls. Indirect and relatively invisible sales taxes at whatever level (production, wholesale, retail) are increasing.

The persistence of a plurality of funding sources may slow the tendency to complete financial control by the central governments even though any tax from any source needs legislative authority. The continuing costs of personal health services are so great that there will be scrounging around for any source to tap whatsoever. Again, Great Britain stands out as a great exception among parliamentary democracies, although there is still a remnant of a payroll tax which helps to support a very small part of the National Health Service. It is reported that the employees have the illusion that this small proportion constitutes the total expenditure for the National Health Service.

It may be that a plurality of funding sources may result in a higher total national expenditure because this total does not become politicized in national policy issues. Great Britain, of course, has an advantage in cost controls by the government's power to set an annual limit to expenditures through treasury policy backed by Parliament. The safety valve here is the small private sector of voluntary health insurance for top level employees and civil servants who want it or can induce their employers to pay for it. This small sector, estimated at 5 percent of total population, and even less than that of expenditures, is now under attack as being inegalitarian. Egalitarianism thus becomes an end in itself, regardless of possible consequences to the flexibility of options in a democratic society.

A persistent but exceedingly unpopular cost control is small charges at time of service to deter casual use of services and goods. All systems apply charges for drugs and medicines, others for dental care, and still others for out-of-hospital physicians' services. Among parliamentary democracies, Great Britain has the fewest and smallest charges. One of the principles of the National Health Service was a free service financed by the general revenue. The issue of site and amount of charges is a constant political issue out of proportion, it seems, to the magnitude of the charges. The trend appears to be the elimination of charges altogether as a deterrence to services.

The private sector in health services delivery, financing, and ownership is an interesting subject area to trace out the history of private sector and public sector interrelationships. All industrialized countries among the parliamentary democracies have permitted the private sector to operate to some degree, the extent to which it can do so reflecting the political philosophy and economic circumstances of the country. Mention has already been made of the private sector in which employees and employers are taxed through payroll deduction to finance health insurance, some allowance being made for private ownership of facilities and autonomous professionals with whom the government contracts.

The heart of the private sector in health services is the opportunity of the citizens to buy services and insurance outside of the mainstream of national health insurance. It seems that there are three types of arrangements in the parliamentary democracies for private sector activity: (1) The private sector can be a safety valve for the mainstream national health insurance system, allowing citizens who wish to avoid the queue 
or see a specialist directly, if the sole entry point is a general practitioner. The British private health insurance arrangement is an example. Even so, the National Health Service is used without charge for major medical procedures which private insurance does not ordinarily cover. Private health insurance buys convenience and reportedly more personal attention from specialists than the National Health Service is established to provide; (2) a second type is as a partner with the government, whereby the existing private insurance agencies act as financial agents for the government in dealing with providers. This arrangement presumably pluralizes power by diffusing financial negotiations throughout the system. West Germany is an example, with its legally private sickness insurance societies since the time of Bismarck. Increasingly, however, as costs become politicized, the government begins to bear down hard on the financial agents to control costs, because such costs are ultimately social costs which affect national accounts; (3) a third arrangement is one in which the private and public sectors have competing systems and citizens can enroll in one or the other. Australia is approaching this type at the moment and Denmark had it, but most governments do not look with favor on competition. The drive is toward monopoly largely under the rationale of equality. There is fear that a two class system will emerge, one for the better off and another for the worse off. In any case, there are vestiges of the private sector in all parliamentary democracies from private ownership of facilities and autonomous, entrepreneurial doctors to separate private insurance arrangements. So far, it seems that the private sector is definitely on the defensive as governments try to control all costs of health services as a matter of public policy. Still, if government health insurance, as defined by upper income groups, is underfinanced and inconvenient, the private sector may expand unless it is proscribed altogether. This is clearly a political question of government legislating consumption which will test the power of the egalitarian drive in parliamentary democracies.

\section{The Issue of Organizational STRUCTURE}

As stated previously, the structure of the delivery system has become a political issue only recently. The health service components have arranged themselves in relation to one another and to funding sources incrementally and largely as determined by the providers. It seems that the general public did not question the emerging arrangements. This is no longer true. The questioning has started; the results are still to be seen.

The classic pattern among parliamentary democracies has been the general hospital for acute diseases, and long-term hospitals for tuberculosis and other chronic diseases. General hospitals have had variable ownership, wholly local government as in Scandinavia, partly local government and private nonprofit ownership as in Great Britain before the National Health Service and on the continent and in North America currently. Long-term hospitals, with few exceptions, have been publicly owned. Among private hospitals, ownership is variable, usually by secular community boards or by churches. The latter 
situation makes nationalization of hospitals more complicated, as, for example, in the Netherlands.

Physicians are autonomous contractors in all systems, in line with the continuing concept of the liberal professionals accorded the prerogative of diagnosis and treatment. What has changed with increasing government intervention is the professions' entreprenurial prerogative to determine the method and amount of payment unilaterally and the organizational arrangement of practice. Ineluctably the physicians' scope has been narrowed to discretion in diagnosis and treatment, and remains intact. In a larger sense, the physician as expert continues to have a dominant role in advising on medical equipment and resources. The trend is toward a salaried service and diminution of fee-for-service method of payment. The latter is regarded as too openended for cost control.

For hospitals the emerging pattern is fixed prospective budgets, within which they must operate for a given period. Also, the trend is toward a reduction of the self-determination. Increasingly, hospitals are being formally classified into so-called district or first-line hospitals and high technology medical centers, with presumably rational and systematic referral procedures between them.

The desired trend for physicians' services, outside of the specialty work in the hospitals, is toward health centers where physicians practice as a group and share equipment and supporting personnel. As funds become more limited, high technology and associated high costs are driving health service organizations to emulate the industrial model. Rationalization is the slogan for an enterprise which defies ra- tionalization according to criteria worked out for automobile manufacturers and life insurance companies.

These trends cut across all countries from the United States to the USSR. The particular stage in the development of a rationalized structure on the industrial model will reflect the political and economic character of each country. In all likelihood, the United States will continue with a more open decisionmaking system than that characteristic of other countries. In the parliamentary democracies, Great Britain will continue to be the most rationalized and structured system approaching the USSR system structurally, but retaining the British style in cross-interest consultations and polite application of guidelines and directives. This style reflects the civic culture. The USSR is the current acme of the centralized planning, financing, and control, with norms and directives sent down through the several layers of administration to the point of delivery. What I am then suggesting is a convergence of health services systems toward a rationalized model with viable boundaries as to regionalization, service unit quotas, and visible and arbitrary budgets. The convergence will not be complete, because of national differences mentioned, but the drive is there. Automobile factories look the same in all countries, but health service systems will differ because they cannot be rationalized along the industrial model to the same degree, regardless of the effort put forth.

\section{The Issue of Planning}

The concept of overall planning of the health services according to cer- 
tain criteria is quite new among parliamentary democracies, even in Great Britain, which has had a rational system according to such criteria since 1948. The USSR has, of course, had a planning concept since the Revolution in 1917, because planning is central to the communist style and method. The systems have evolved incrementally until, suddenly, there is a cost explosion which frightens governments into searching for methods to contain it.

This method is overall planning. Indeed, the United States is unique in that a health planning act has been legislated before the enactment of national health insurance. The United States is considering national health insurance at a time when health costs are rising; other countries enacted national health insurance when health costs were relatively stable. National health insurance did not cause increased health care costs though it probably exacerbated them. Costs would have risen anyway, given the increasingly costly technology and rising incomes.

Because it is the most expensive component, the service component receiving major attention in planning is the hospital. The prevailing view everywhere is to slow, or even stop, the expansion of the hospital component and expand the primary physician services and other out-ofhospital services. The Swedes and the Russians appear to lead the way in accumulating data on facilities and personnel, and according to certain norms of need, age being the most important one, projecting these components five, ten, and more years into the future. Great Britain is paying great attention to planning, also with the usual variety of need/ demand standards of the conven- tional kind. That country, however, is placing much emphasis on equalizing distribution of facilities and personnel as an integral part of its planning for equality of access to public systems. Canada and the continental countries are seriously trying to engage in planning and regionalization, but so far detailed planning is still not legislated. The prevailing method, which can be called negative planning, is for the government to control hospitals and other facilities through regulation. The dominant concept everywhere is to limit supply, since it does not seen practical to limit or control demand any other way. There is also increasing control in costs through regulation.

The current status of the art and science of health services planning is very crude. The relationship of need to demand in facilities and personnel and their financing are difficult to specify in a scientifically valid way. Hence, quite arbitrary criteria are established which can be tested against public and professional tolerance as to convenience and quality. The criteria are then essentially political; that is, what is the balance, even temporarily, between the interest groups? Until recently, all systems experienced a euphoria of expansion; no interest group really gave up anything except by feeling relatively deprived compared to other groups. In the next decade there will be hard bargaining by interest groups in all countries, government being in the strongest position as the major source of funding.

As part of the planning context, there is increasing interest in interrelating professional health services and social services. There is a gray area blurring the boundaries of the 
health services system in which it is difficult to determine whether a patient has primarily a medical problem, which should be handled by technical health personnel, or a more diffuse social problem with a health component, which health personnel want to unload on the social services. No country appears yet to have resolved this interrelationship. Professional status and prerogatives and budget allocations are involved. In the long run I would predict that medical care will become increasingly high technology, and the uninteresting and unrewarding patients, medically, will be channeled to the social services, including the already beseiged nuclear family. More needs to be known about the interrelationship of family structure, ill and incapacitated members, and the helping professions. At the moment the social system does not show signs of being able to absorb gracefully the increased chronic illness problems. The storehouses are here called nursing homes; indeed, they started with mental hospitals.

The extent to which rational planning is possible is still to be tested. Given the paucity of validated performance indicators, as I have mentioned, I do not see how rational planning is possible, even if the planners have power and there is conformity to the plan. Planning will be successful; that is, acceptable, if a health care system is generously financed and proportioned. If the health system is tightly controlled and tightly financed, there will be restiveness among both the public and the health professionals. Each country will find its own equilibrium, and it is likely that the acceptable balance in the United States will continue to be more costly than that in Great Britain. Other countries among the parliamentary democracies will range themselves in between.

\section{OBSERVATIONS AND CONCLUSIONS}

From a review of the experiences of a number of health services systems across countries, it can be reasonably generalized that we have learned the following:

1. Universal health insurance effectively protects the family from high-cost medical episodes.

2 . It can be inferred that access to services becomes more equalized across income classes by eliminating large charges at time of service.

3 . The equal distribution of services geographically is not achieved by universal health insurance alone, unless there is a policy built into the health insurance implementation. Even then, equal distribution is very difficult even to approximate. There is a limit to which any government is able and willing to allocate resources geographically, particularly personnel.

4. The overall costs of a health services system are not controlled by any particular organizational structure or funding methods. It appears that the amount a society is willing to spend on health services is almost purely a political decision independent of the structure of the delivery system. Given a public policy of stringent cost control, it is, however, easier to control costs in a centralized funding system than in a decentralized one.

5. Professional freedom to diagnose and treat continues in governmental systems as a prerogative of the professional and the expert. This will continue, although the profes- 
sional will be increasingly challenged as to the need for certain expensive resources. The profession will remain in a dominant position as long as the public fears pain and death as much as it does today.

6. As an aspect of professional freedom, patient choice of physician is possible and continues, although in more constricted circumstances than in pure private practice. Systems need to control intake in some way by limiting their entry points.

7. Pluralistic funding is probably more expensive in total than centralized funding is because it is more difficult to exercise cost controls; and cost, as a national political issue, becomes more diffused in a pluralistic funding system than in a centralized one.

8. Although small charges at time of service persist, particularly for out-of-hospital services, these charges are very unpopular among the public. They will probably be eliminated in time.

9. The comprehensiveness of the service offered or paid for by national health insurance continues to expand. The trend appears to be in the direction of a health service rather than health insurance for major contingencies. The public appears loath to pay out-of-pocket for any health service.

10. The private sector is diminishing in scope and power as a countervailing force; in fact, in Europe, it was never regarded as a countervailing force or competitor. The private health insurance sector, when one existed before universal health insurance, was always regarded as deficient with respect to scope of benefits and proportion of the population covered, especially self-employed, low-income, and aged. Still, politically, the private sector was never given criteria by which to measure a politically satisfactory level of achievement. Health services objectives appear to be inherently utopian, in which case government responsibility and control is the ultimate step. After that there is nowhere to go, although the desire for utopian objectives persists.

11. The trend for hospitals is regulation of expansion and construction and fixed annual budgets with little room for negotiation. The trend for physicians outside of the hospital is toward regulated or negotiated fixed fee schedules. Inside the hospital the standard payment method has been salary by hierarchy. The fee-for-service method of payment continues to be popular among physicians and unpopular among administrators, but it is amazingly tenacious, indicating something inherent in a professional and personal service.

12. All systems continue to be acute illness crisis-oriented; thus, the major portion of the resources go to acute illnesses and sophisticated technology, and the health professionals are more interested in crisis care than long-term medical care management of chronic illness.

13. There seems to be a lot of lip service to, but little action in, preventive care, except for the traditional maternal and child health programs. The now burgeoning interest in changing life styles-smoking, overeating, overdrinking-conceivably could reduce pressure on the health services. This still is largely rhetoric with faddist overtones, and I do not believe life style changes can progress sufficiently to lessen impact on the personal health services.

14. It appears that the public is interested in more health services than public authorities are willing to 
finance in relation to other national priorities. It would seen that the public needs to be given more knowledge of relative costs and tradeoffs. Public budgets are too murky for this type of citizen education.

15. The interest in the industrial model is pervasive, but industrial engineers and management technicians have not yet entered the health services in full force. Health services administration will be too soft for full application of the industrial model. The health professionals will resist and sabotage such efforts, and, in my mind, quite legitimately.

16. Systematic planning is in its infancy. Validated norms have yet to be established and the possibility of local conformance to a general plan has yet to be tested. There is a lot of internal negotiation at present.

17. The seeming trend toward national health services to integrate families, personal health services, and social services, and treat families as units is a move from an individualistic-atomic model, characteristic of parliamentary democracies and pluralistic systems, to collective-organic models, products of the emerging welfare state, democratic socialism, and communism. The role of the individual, family, private and public sectors, and the state will have to be thought through in another context.

18. Finally, systems do not learn from one another; they copy each other incrementally, in the context of each country's economic, social and political matrix. Medical care techniques are picked up rapidly, but health services systems evolve. There is no correct system in the sense that there is a well-functioning automobile factory which can be dismantled in Italy and reassembled or copied process for process in the USSR.

\section{What Will Happen in the UNITED STATES?}

What is likely to happen in the United States? I am of the opinionnot wholly without evidence-that it is easier to predict what will happen than to recommend an overall policy, which is not politically feasible, although medically desirable. Accordingly I will predict rather than recommend.

As stated earlier, the United States is facing a full range of problems simultaneously, while considering universal health insurance. This is evident in the legislation and the debates. Lacking a policy consensus politically and a clear concept of what to do, the United States is entertaining legislation which runs the gamut from a British-type national health service to a private enterprise insurance concept of covering high-cost contingencies. The British-type enters into the very structuring of the system through the centralized funding mechanism. The contingency-type simply pays for high-cost episodes and lets the delivery system evolve in a more or less market context. This is why, I believe, there has evolved the range of delivery types in this country which is not true elsewhere. Given the plethora of interest groups active, it is clear why there will be some initial legislation between these two extremes. I would hazard a guess that the mass of the public is more concerned with high-cost episodes and relative conveniences of access at night and weekends than it is with reorganization of the system. The latter is a very technical problem which may well elude the general public, but high out-of- 
pocket costs and difficulty of access are salient. ${ }^{6}$ This does not preclude the need, of course, for organizational changes to meet the public's dissatisfaction.

The following predictions are made:

1. Pluralistic funding will continue because of the reluctance to have public costs reflected in the national budget and the progressive income tax.

2. Universality will be hotly debated, and it is a toss-up whether or not there will be blanket coverage or more chopping off of age groups such as children. The aged are a precedent.

3. Private carriers will likely be intermediaries in the current Medicare arrangement in order to slow the growth of a federal bureaucracy.

4. It is very likely that at least some type of catastrophic insurance will be the easiest to pass. Medicaid will likely be federalized. The states find the burden onerous.

5. Simultaneously, there will be attempts to control the supply, particularly hospital beds, through regulation and the involvement of the Planning Act (PL 93-641).

6 . There will be continuing attempts to monitor physician decisionmaking in hospitals through

6. See, Ronald Andersen, Joanna Kravits, and Odin W. Anderson, "The Public's View of the Crisis in Medical Care: An Impetus for Changing Delivery Systems?", Economic and Business Bulletin (Fall 1971), pp. 44-52.
Professional Standards Review Organizations (PSROs), but the medical profession will control it. ${ }^{7}$

7. The Planning Act PL 93-641 will create Health Service Areas for local interest group bargaining, but it will be loosely structured. Federal sanctions will be gentle.

8. The private insurance sector will continue to flourish even in the event of universal health insurance because, traditionally, in the United States (as in Great Britain), financing will be tight. We inherited Britain's public niggardliness. The result may be a bulging of the private sector unless it is proscribed, an unlikely possibility.

9. Finally, the health system will continue to have a high technology emphasis disease by disease: renal dialysis is a good example. Priorities will be spontaneous rather than planned.

In sum, the American public is not familiar with a universal governmental system, and is unfamiliar with restrictions on resources and access, like queues, and it does not have the civic consciousness to discipline itself collectively. The next ten years will provide ample opportunity for social research in the health politics of the American political system.

7. Odin W. Anderson, "PSROs, the Medical Profession and the Public Interest," Health and Society (Summer 1976), pp. 379-88. 